\title{
O SUJEITO DA PRÁXIS DE LIBERTAÇÃO NA FILOSOFIA TRANSMODERNA
}

\author{
Walter Guandalini Jr."
}

Aqui nessa casa ninguém quer a sua boa educação Nos dias que tem comida comemos comida com a mão E quando a polícia, a doença, a distância ou alguma discussão Nos separam de um irmão, Sentimos que nunca acaba de caber mais dor no coração. Mas não choramos à toa, Não choramos à toa.

Aqui nessa tribo ninguém quer a sua catequização. Falamos a sua língua, mas não entendemos seu sermão. Nós rimos alto, bebemos e falamos palavrão

RESUMO: O presente artigo tem por objetivo realizar uma análise das características do sujeito da práxis de libertação na filosofia transmoderna, segundo o pensamento de Enrique Dussel. Partindo da constatação da negação da vida humana como resultado indesejado de mais de quinhentos anos de Modernidade eurocêntrica, o autor protesta pela necessidade de se negar a própria negação, tomando como referente privilegiado da práxis de libertação as próprias vítimas, que, em sua corporalidade, e organizadas em uma comunidade intersubjetiva, assumem a responsabilidade pela libertação.

* Mestre e Doutorando em Direito do Estado (UFPR), professor da Faculdade de Direito Dom Bosco e
Mas não sorrimos à toa.

Não sorrimos à toa.

Aqui nesse barco ninguém quer a sua orientação. Não temos perspectiva, mas o vento nos dá a direção. A vida que vai à deriva é a nossa condução. Mas não seguimos à toa. Não seguimos à toa.

Volte para o seu lar, Volte para lá.

Arnaldo Antunes - Volte para o seu lar

RESUMÉ: L'objectif de cet article est d'analyser les caractéristiques du sujet de la praxis de libertation dans la philosophie transmoderne, selon la pensée d'Enrique Dussel. Partant de la constatation de la négation de la vie humaine comme consequénce indésirée de plus de cinq cents ans de Modernité eurocentrique, l'auter proteste pour la necessitée de se nier la propre négation, prenant comme référence privilégiée de la praxis de libertation les victimes elles-mêmes, que, en ses corporalités, et organisées dans une communauté intersubjective, prennent la responsabilité de sa libertation.

da Faculdade de Direito Opet, procurador da Companhia Paranaense de Energia. 


\section{INTRODUÇÃO}

O presente artigo tem por objetivo realizar uma análise das características do sujeito da práxis de libertação na ética da libertação de Enrique Dussel. Partindo da constatação da negação da vida humana como resultado indesejado de mais de quinhentos anos de Modernidade eurocêntrica, o autor protesta pela necessidade de se negar a própria negação, mediante a afirmação da alteridade da vítima (exterior ou interior ao sistemamundo da Modernidade) e do dever ético de produção, reprodução e desenvolvimento da vida concreta de cada sujeito humano como condição de possibilidade da ação humana o que o torna fundamento de toda a sua construção teórica.

Mas a mera reprodução da vida não é suficiente; assim, Dussel defende serem os momentos necessários da ética, no campo da afirmação: a) o momento material, com pretensão de verdade prática universal, no qual é estabelecido o dever ético de se garantir a produção, reprodução e desenvolvimento de todo ser humano ${ }^{1}$ (uma conduta é verdadeira se garante a vida); b) o momento formal, com pretensão de validade procedimental

${ }^{1} \mathrm{O}$ enunciado do princípio material universal afirma que "aquele que atua eticamente deve (como obrigação) produzir, reproduzir e desenvolver autoresponsavelmente a vida concreta de cada sujeito humano, numa comunidade de vida, a partir de uma 'vida boa' cultural e histórica (seu modo de conceber a felicidade, com uma certa referência aos valores e a uma maneira fundamental de compreender o ser como dever-ser, por isso também com pretensão de retidão) que se compartilha pulsional e solidariamente, tendo como referência última toda a humanidade, isto é, é um enunciado normativo com pretensão de verdade prática e, além disso, com pretensão de universalidade" (DUSSEL, 2002:143 - grifos no original). universal, no qual é estabelecido o dever ético de se tratar com simetria todos os participantes da comunidade de comunicação, buscando-se atingir o consenso intersubjetivo² (uma conduta é válida se aceita em consenso através de um procedimento argumentativo por todos aqueles a quem atinge); e c) o momento da factibilidade, com pretensão de bondade, no qual se analisa a possibilidade de libertação da vítima diante dos sistemas dominantes ${ }^{3}$ (uma conduta é boa se, além de verdadeira e válida, é capaz de transformar a realidade geradora de vítimas).

Acontece, porém, que os seres humanos não têm capacidade de ação e conhecimento

${ }^{2}$ Segundo o princípio moral formal universal, "quem argumenta com pretensão de validade prática, a partir do re-conhecimento recíproco como iguais de todos os participantes que por isso mantêm simetria na comunidade de comunicação, aceitas as exigências morais procedimentais pelas quais todos os afetados (afetados em suas necessidades, em suas conseqüências ou pelas questões eticamente relevantes que se abordam) devem participar faticamente na discussão argumentativa, dispostos a chegar a acordos sem outra coação a não ser a do argumento melhor, enquadrando esse procedimento e as decisões dentro do horizonte de orientações que emanam do princípio ético-material já definido" (DUSSEL, 2002:216 - grifos no original).

${ }^{3}$ De acordo com o princípio de operabilidade "aquele que opera ou decide eticamente uma norma, ação, instituição ou eticidade sistêmica deve cumprir: (a) com as condições de factibilidade lógica e empírica (técnica, econômica, política, cultural, etc.), isto é, que seja realmente possível em todos esses níveis, a partir do marco (b) das exigências: (b.1) ético-materiais da verdade prática e (b.2) morais-formais discursivas da validade, dentro de uma escala que vai desde (b.i) as ações permitidas eticamente (que são as meramente 'possíveis', que não contradizem os princípios ético ou moral) até (b.ii) as ações devidas (que são as eticamente 'necessárias' ao cumprimento das exigências humanas básicas: materiais - de reprodução e desenvolvimento da vida do sujeito humano - ou formais - desde o respeito da dignidade de todo sujeito ético até a participação efetiva e simétrica dos afetados nas decisões) (DUSSEL, 2002:272 - grifos no original). 
irrestritos; por ser limitada, toda ação humana será geradora de vítimas, de modo que se torna necessário efetuar também a crítica dessas ações, mesmo que sejam boas e cumpram os três requisitos enumerados anteriormente. É o que se faz nos três momentos posteriores da ética: $d$ ) o momento da crítica material, no qual se critica a existência de vítimas nãointencionais do sistema que busca a afirmação da vida $\left.{ }^{4} ; e\right)$ o momento da crítica formal, no qual se almeja a construção de uma nova validade intersubjetiva, anti-hegemônica, a partir da comunidade das vítimas ${ }^{5}$; e $f$ ) o momento da nova factibilidade de libertação, que ao criar novos conteúdos exige o desenvolvimento libertador da vida negada, a partir da invenção de frentes de libertação que a afirmem. ${ }^{6}$

\footnotetext{
${ }^{4}$ Segundo o princípio ético-crítico, "os que agem ético-criticamente re-conheceram a vítima como ser humano autônomo, como o Outro, como outro que a norma, ato, instituição, sistema de eticidade etc., ao qual se negou a possibilidade de viver (em sua totalidade ou em algum de seus momentos); de cujo re-conhecimento simultaneamente se descobre uma co-responsabilidade pelo outro como vítima, que obriga a tomá-la a cargo diante do sistema, e, em primeiro lugar, criticar o sistema (ou aspecto do sistema) que causa esta vitimação. O sujeito último de um tal princípio é, por sua vez, a própria comunidade das vítimas” (DUSSEL, 2002:380 grifos no original).
}

${ }^{5} \mathrm{O}$ enunciado do princípio ético crítico-discursivo comunitário de validade afirma que "aquele que age ético-criticamente deve participar (sendo vítima ou articulado como 'intelectual orgânico' a ela) em uma comunidade de comunicação de vítimas que, tendo sido excluídas, se reconhecem como sujeitos éticos, como o outro enquanto outro que o sistema dominante; aceitando simetricamente sempre para fundamentar a validade crítica dos acordos a argumentação racional, motivados por uma pulsão solidário-alterativa criadora" (DUSSEL, 2002:469 - grifos no original).

\footnotetext{
${ }^{6}$ Para a nova factibilidade. "aquele que opera éticocriticamente deve (está obrigado a) libertar a vítima, como participante (por 'situação' ou por 'posição' -
}

A discussão acerca do sujeito que irá efetuar a práxis de libertação se enquadra principalmente no último momento da Ética da Libertação. Isso porque essa discussão diz respeito à emergência de novos sujeitos sócio-históricos, à formação de uma comunidade de vítimas que seja capaz de, pela ação política organizada, transformar o sistema que nega a vida e gera vítimas, em uma práxis de libertação.

Dussel (2002:519) parte do pressuposto de que todo indivíduo concreto, em seu agir cotidiano, já é um sujeito possível da práxis de libertação, como vítima ou solidário com a vítima, enquanto fundamentar normas, realizar ações, organizar instituições ou transformar sistemas de eticidade em prol da libertação da vítima e da reprodução da vida. Mas apenas isso não é suficiente; para a Ética da Libertação a subjetividade deve ser redefinida de maneira flexível, complexa, fluida, pensando os diversos lugares da enunciação em tensão de mútua co-constituição: nem sujeito metafísico, nem não sujeito, mas “diversidade subjetiva como diagrama" (DUSSEL, 2002:582).

A partir desses pressupostos, o referente privilegiado da práxis de libertação é a própria vítima, que atua como sujeito

diria Gramsci) da própria comunidade a que pertence a vítima, por meio de a) uma transformação factível dos momentos (das normas, ações, microestruturas, instituições ou sistemas de eticidade) que causam a negatividade material (impedem algum aspecto da reprodução da vida) ou discursivo-formal (alguma simetria ou exclusão da participação) da vítima; e b) a construção, através de mediações com factibilidade estratégico-instrumental críticas, de novas normas, ações, microestruturas, instituições ou até sistemas completos de eticidades onde essas vítimas possam viver, sendo participantes iguais e plenos" (DUSSEL, 2002:565 - grifos no original). 
em prol de sua libertação. Esse sujeito é dotado de três características básicas que o aproximam do sujeito de que fala a canção de Arnaldo Antunes, e é a partir dessas três características que será analisado neste trabalho: em primeiro lugar, trata-se de um sujeito corporal, simultaneamente biológico e cultural, que sente fome e dor no coração, e que deseja que seus sofrimentos físicos e morais sejam aplacados. Além disso, reafirma-se o imperativo de que a própria vítima seja vista como sujeito da práxis de sua libertação, o que torna desnecessária qualquer espécie de "catequizadores", vanguardas emancipatórias ou lideranças políticas. Finalmente, esses sujeitos não agem solipsisticamente, mas unidos em uma intersubjetividade comunitária, por meio da qual se forma um consenso anti-hegemônico que determina a direção do movimento e busca a transformação da realidade que nega suas vidas concretas. É o que veremos a seguir.

\section{CONTRA A FALTA DE COMIDA E A DOR NO CORAÇÃO: A CRÍTICA DO SUJEITO TRANSCENDENTAL E O SUJEITO CORPORAL VIVO}

A negação do sujeito moderno é o ponto de partida do qual Dussel constrói uma nova forma de subjetividade, radicalmente distinta dele. O filósofo argentino examina o pensamento de uma série de autores fundamentais para a construção teórica do sujeito moderno, mas manteremos o foco nos principais deles: René Descartes e Immanuel Kant.

A partir das reflexões de Descartes (1961), o sujeito passa a ser visto como uma alma descorporalizada, cuja função é essencialmente cognitiva. O filósofo dá início, assim, ao racionalismo moderno, que restringe o ego ao cogito e parte do pressuposto de que o pensamento é capaz de, por si só, encontrar a verdade. Até então, não se acreditava na capacidade do homem de alcançar a verdade sem um trabalho sobre sua alma, sobre si mesmo (FOUCAULT, 2001c); com o advento da modernidade, porém, a busca da verdade se torna independente deste "cuidado de si", podendo ser realizada unicamente com base na atividade racional do homem, por meio de um método impessoal, passível de ser utilizado por todo e qualquer indivíduo. Desse modo, o fundamento do pensamento filosófico deixa de ter um substrato corporal ou espiritual, o que inaugura uma nova forma de fundamentação da filosofia.

O pensamento de Kant (1999) também foi fundamental para a constituição da subjetividade moderna. Para o pensador alemão, o conhecimento está vinculado a condições presentes no próprio sujeito, e a razão que desvenda o conhecimento é autônoma também para determinar os princípios éticos que irão conduzir a vida do indivíduo, que é capaz de os estabelecer para si de forma livre e racional.

Assim, o panorama estabelecido pelo pensamento moderno apresenta o sujeito como o fundamento da vida em sociedade, da organização política e do conhecimento. Esse sujeito, em primeiro lugar, é um sujeito universal, porque nesta categoria se encaixam todos os seres humanos, sem espaço para particularismos; é um sujeito individual porque o homem é considerado como ser concreto e independente, detentor do direito 
de sua auto-satisfação; é um sujeito autônomo porque livre e capaz para pensar e agir por si mesmo; finalmente, é um sujeito abstrato, uma vez que qualquer homem empírico pode ser enquadrado na categoria, tendo a capacidade de - por meio de um método racional e impessoal - atingir a verdade sobre as coisas, e de estabelecer de maneira livre e racional os princípios éticos que irão reger sua própria existência (ROUANET, 1993). Dessa forma o sujeito transcendental perde, em seu formalismo, o critério material do conteúdo ético dos atos humanos, só lhe restando a validade vazia e a racionalidade sem corporalidade (DUSSEL, 2002:521).

Acontece que a subjetividade da consciência já está sempre na realidade, pressupondo o horizonte de uma posição ontológica de existência no mundo. Antes do conhecer explícito do cogito, o sujeito já está inserido no mundo empírico, na faticidade pré-cognitiva. Como percebe Foucault $^{7}$ (2001b), os filósofos modernos partem da análise de um sujeito empírico para transcendentalizá-lo, construindo uma abstração que se torna padrão de referência e fundamento de compreensão do próprio sujeito empírico. O saber obtido acerca do homem empírico é colocado acima dele e do mundo, o define, o transcendentaliza, e o abstrai em uma categoria transcendental e universal, que passa a explicar o próprio homem: o Sujeito. Este Homem transhistórico, contudo, não passa de uma

${ }^{7}$ Foucault, que chega a essas conclusões a partir da filosofia de Heidegger, é apenas um dos diversos filósofos mencionados por Dussel em sua crítica do sujeito transcendental da Modernidade. Privilegiamos o seu pensamento porque o consideramos o mais útil para a crítica que está sendo realizada neste momento. abstração do homem empírico, que não é e nem pode ser natural e universal, pois é um homem que foi construído historicamente, resultado das inter-relações entre as diversas formas de poder de uma episteme historicamente vigente.

Porém, em vez de analisar a constituição histórica de um sujeito que se pretende universal no tempo e no espaço, como faz Foucault, Dussel se concentra na crítica de um sujeito que se pretende apenas razão. A partir principalmente do pensamento de Lévinas, que enxerga a subjetividade a partir da corporalidade do prazer e como responsabilidade pelo outro, o autor afirma o sujeito corporal vivo como fundamento da Ética da Libertação.

Como demonstra Dussel, todo ato cognitivo pressupõe um sujeito humano concreto vivo como último critério de subjetividade, como ponto de partida. ${ }^{8}$ A vida humana concreta é permanentemente referência e conteúdo da consciência cognoscente, do mundo, da linguagem, dos instrumentos e valores culturais, de todos os sistemas performativos, da discursividade e da comunidade de comunicação. Portanto, deve-se ter em conta os sujeitos vivos que operam nos sistemas performativos como partes funcionais; e deve-se tê-los em conta não como entidades racionais, ou como vontades autônomas, mas como seres corporais vivos, capazes de sentir dor e

${ }^{8}$ Para utilizarmos um exemplo do próprio Dussel (2002:527), o "Mercado" como entidade abstrata depende, em última instância, no mínimo da vida concreta dos operadores da bolsa que se cansam, devem dormir, comer, não podem trabalhar mais de oito horas por dia, sentem tristeza, alegria, dores físicas e espirituais etc. 
prazer, fome e tristeza, dor no estômago e no coração, e que como tais devem ser tratados. Nas palavras de Dussel:

Reintroduzir, como um momento fundamental, uma referência à vida-morte [...] é ter em conta os sujeitos vivos que operam nos sistemas performativos como "partes funcionais". O juízo de fato crítico [...] é enunciado como a possibilidade da produção, reprodução e desenvolvimento da vida dos sujeitos reais do sistema, e como critério de seus fins: se a vida não é possível, a razão instrumental que se exerce em torná-la impossível é eticamente perversa (DUSSEL, 2002:539 - grifos no original).

Assim, o sujeito da práxis da libertação é, em primeiro lugar, um sujeito vivo, natural e cultural. A libertação não pode ser meramente a libertação da razão ou da vontade, então; uma libertação real deve tomar em conta o homem como ente moral e corpóreo, tendo como objetivo (mesmo que nunca plenamente alcançável) a eliminação de seus sofrimentos físicos e psíquicos. Além disso, a estratégia elaborada pela práxis libertadora no sentido da construção da nova factibilidade deve ter sempre em mente o fato de que os próprios agentes da libertação são, também, sujeitos corporais-morais vivos (com todos os seus limites biológicos), e não apenas "razão revolucionária" - contrariamente às práticas políticas tradicionais da esquerda, como mostra o depoimento de Fernando Gabeira sobre sua atuação política durante a Ditadura Militar:

Os operários é que iriam decidir tudo, a médio e longo prazo. Mas não éramos operários. Minhas primeiras tarefas consistiam, exatamente, em contribuir para a vinculação do grupo com os operários. Como? Acordávamos às cinco da manhã, tomávamos o Volks que eu tinha e seguíamos para as fábricas, a fim de distribuir propaganda e discutir com os eventuais interessados. Ficávamos naquela propaganda até as sete horas em ponto, quando os operários já tinham entrado na fábrica. Dali, voltávamos todos para o centro, onde ia começar a trabalhar no JB, por volta de sete e meia. Meu corpo por vezes transigia. Era preciso um despertador bem forte, para nos colocar fora da cama às cinco e meia. As noites eram passadas em discussões, leituras, às vezes em pura vagabundagem amorosa. Todos os dias, o despertador tocava à mesma hora e nem sempre o corpo se movia. Problema ideológico, dizia o assistente. Era o termo que se usava, e creio que se usa ainda, para analisar nossas fraquezas (GABEIRA, 1979:51).

\section{CONTRA A CATEQUizaÇÃO: A CRÍTICA DOS VANGUARDAS E A VÍTIMA COMO SUJEITO}

Além da negação do sujeito moderno, também é um pressuposto para a construção do sujeito da práxis libertadora na Ética da Libertação a negação de toda vanguarda ou liderança emancipadora. A vítima não compreende, não deseja e não necessita de qualquer espécie de catequização ou conscientização que venha de outro local que não seja ela mesma; é a própria vítima, portanto, que assume a consciência de sua situação de vítima e luta para se libertar dessa situação. Nesse sentido é bastante útil, para a compreensão deste processo, uma breve análise da Pedagogia do Oprimido de Paulo Freire (1974).

De acordo com Paulo Freire, a tarefa do educador não pode se resumir apenas ao aspecto cognitivo, devendo incluir também o aspecto ético-crítico, de modo a tornar possível a superação da situação real de opressão. Para isso, os oprimidos devem se reconhecer como homens em sua vocação ontológica e histórica de Ser Mais (FREIRE, 1974:57). 
Mas, como afirma o educador, "precisamos estar convencidos de que o convencimento dos oprimidos de que devem lutar por sua libertação não é doação que lhes faça a liderança revolucionária, mas resultado de sua conscientização" (1974:58 - sem grifos no original). Assim, é necessário que a própria vítima tome consciência de sua situação de opressão, momento a partir do qual ela mesma inicia a luta por sua libertação. Dispensa-se, portanto, a doutrinação pelas lideranças, ou a ação política das vanguardas; qualquer ação tomada à revelia dos oprimidos não é uma ação libertadora, pelo simples fato de que, se a própria vítima não atua como sujeito de sua libertação, ela jamais se liberta realmente. Os oprimidos devem chegar como sujeitos, não como objetos, ao conhecimento da situação de opressão; é como homens que eles devem lutar, não como coisas (FREIRE, 1974:60).

Para lutar como homens, porém, é necessário que tomem consciência de sua situação de opressão. Essa tomada de consciência não ocorre a partir da mera doutrinação por parte da intelectualidade transformadora, o que manteria o oprimido em situação de objeto, instrumentalizado pela liderança revolucionária. É necessário um processo de conscientização, de desenvolvimento crítico da tomada de consciência, por meio do qual se supera a fase espontânea de apreensão da realidade para se alcançar a fase crítica, em que a realidade se torna um objeto cognoscível e passível de ser avaliado ético-criticamente. Isso se faz através de uma concepção problematizadora da educação, pela qual ninguém educa a ninguém e ninguém se educa sozinho, mas os homens se educam entre si, mediatizados pelo mundo (FREIRE, 1974:98). Nessa prática o educador não se limita a depositar sobre o educando conteúdos previamente estabelecidos, mas, em uma ação dialógica, faz com que o educando tome consciência da objetividade em que está inserido e aumente o nível de percepção de si mesmo e do mundo em que e com que está (FREIRE, 1974:101). O educador crítico, então, não ensina ao oprimido a sua situação de vítima; ele apenas possibilita o descobrimento da condição de vítima pelo próprio educando. No processo de conscientização a consciência não chega de fora, pela catequização, mas surge de dentro da própria consciência do educando, despertada pelo educador (DUSSEL, 2002:439). A vítima se torna, assim, sujeito de sua própria libertação.

Posição similar é assumida por Michel Foucault e Gilles Deleuze, em entrevista recíproca a respeito da relação entre intelectuais e poder. Para eles, o objetivo dos intelectuais não deve ser uma "tomada de consciência das massas", mas o combate ao lado dos que lutam pela destruição progressiva do poder. Segundo Deleuze:

O intelectual teórico deixou de ser um sujeito, uma consciência representante ou representativa. Aqueles que agem e lutam deixaram de ser representados, seja por um partido ou um sindicato que se arrogaria o direito de ser a consciência deles. Quem fala e age? Sempre uma multiplicidade, mesmo que seja na pessoa que fala ou age. Somos todos pequenos grupos. Não existe mais representação, só existe ação: ação de teoria, ação de prática em relações de revezamento ou em rede (FOUCAULT, 2004a:70).

Assim, as relações entre teoria e prática deixam de ser concebidas como um processo de totalização, mas em uma relação de mútua complementaridade, em que a 
teoria supera barreiras encontradas na prática, e a prática supera obstáculos da teoria. O papel do intelectual é transformado, como explica Foucault:

O que os intelectuais descobriram recentemente é que as massas não necessitam deles para saber; elas sabem perfeitamente, claramente, muito melhor do que eles; e elas o dizem muito bem. Mas existe um sistema de poder que barra, proíbe, invalida esse discurso e esse saber. [...] Os próprios intelectuais fazem parte desse sistema de poder, a idéia de que eles são agentes da "consciência" e do discurso também faz parte desse sistema. O papel do intelectual não é mais o de se colocar "um pouco na frente ou um pouco de lado" para dizer a muda verdade de todos; é antes o de lutar contra as formas de poder exatamente onde ele é, ao mesmo tempo, o objeto e o instrumento: na ordem do saber, da "verdade", da "consciência", do discurso (FOUCAULT, 2004a:71).

Então é o sujeito negado, a própria vítima, que atua como sujeito da práxis de libertação. É o sujeito que aparece em toda a sua clareza nas crises dos sistemas, como Outro que o sistema, oprimido ou excluído, vítima não-intencional como efeito da lógica performativa do todo formal racionalizado, que mostra sua irracionalidade a partir da vida negada da vítima (DUSSEL, 2002:529).

Todavia, a subjetividade empírica, viva, corporal, aparece na vítima como interpelação; o sujeito já não pode viver e grita de dor: "Tenho fome! Dê-me de comer!". Ao interpelar os que não são vítimas, gritando a eles sua opressão real, os torna responsáveis por sua opressão e os co-responsabiliza por sua libertação - se o outro é a vítima possível causada por minha ação funcional no sistema, então eu sou responsável e devo libertá-lo. Desse modo a vítima empírica, cuja vida está em risco, age em prol de sua libertação, mas também interpela os que não são vítimas, tornando-os co-responsáveis pela sua libertação do sofrimento físico e moral. Aquele que não é vítima, assumindo-se como causa da vitimização do Outro e assumindo a responsabilidade por sua libertação, passa a desenvolver também uma práxis de libertação, ao lado da vítima e liderado por ela. Então, o sujeito da práxis de libertação é primordialmente o sujeito necessitado (a comunidade de vítimas empíricas), mas também aqueles que, após a interpelação, se tornam co-responsavelmente articulados a ele (DUSSEL, 2002:530).

\section{CONTRA A ORIENTAÇÃO: PARA NÃO SEGUIR O CAPITÃo, AS INTERSUBJETIVIDADES COMUNITÁRIAS NO COMANDO DO LEME}

Contudo, a vítima não age individualmente; é necessária a sua união, para a formação de uma comunidade de vítimas, uma subjetividade intersubjetiva que se constitua a partir de uma comunidade de vida, desde uma comunidade lingüística, uma memória coletiva, necessidades semelhantes, uma cultura e uma tradição semelhantes, aspirações compartilhadas e uma situação concreta de opressão. "São os movimentos sociais, momentos de uma microestrutura de poder, de instituições, de sistemas funcionais produtivos, classes sociais, etnias, regiões, povos inteiros, nações, países, estados etc." (DUSSEL, 2002:531).

Na verdade, ao realizar essa análise Dussel não está apenas rejeitando a possibilidade de ação política individualista; ele critica também a construção tradicional da "classe" 
como sujeito "natural", por meio da qual se investe o sujeito inter-subjetivo de uma subjetividade substancial inexistente, o que o torna um dos sujeitos metafísicos tão característicos da modernidade (DUSSEL, 2002:530).

Assim, os novos sujeitos sócio-históricos não devem ser vistos como um sujeito natural, metafísico (a classe, o partido); os sujeitos da ação política na transmodernidade são os movimentos sociais, que aparecem em conjunturas bem determinadas, resultado de uma comunidade de vida das vítimas, que lutam lutas locais e específicas.

Esses sujeitos sócio-históricos se formam em um lento processo, cuja primeira etapa é a própria existência da comunidade de vítimas, fruto de um sistema performativo, com uma identidade que se afirma como diferença diante de outros grupos. Neste ponto o dominado ainda não tem consciência éticocrítica, não enxerga a sua situação de sujeição, mas é este o ponto de partida da reflexão ético-estratégica. Ele apenas existe como comunidade de vítimas, que se afirma como diferença perante os outros grupos sociais.

No entanto, o surgimento de novos sujeitos pressupõe um processo ético de passagem de um grau de subjetividade passiva a graus de maior autoconsciência, o que leva à formação de uma subjetividade crítica. A intersubjetividade das vítimas supera o estágio de falsa consciência e passa a perceber criticamente a realidade ao redor, de dominação, opressão e exclusão. É ainda um momento negativo, passivo, no qual apenas se forma a consciência de classe que permite vislumbrar a situação de sujeição.

A formação de uma subjetividade agente na história exige uma nova etapa, na qual se efetua uma crítica autoconsciente do sistema que causa a vitimação. O sujeito sócio-histórico se torna uma subjetividade libertadora quando é capaz atingir uma consciência crítico-explicativa da causa de sua negatividade. Conhecendo as causas de sua negatividade, a comunidade de vítimas assume a capacidade de lutar contra elas, procurando a transformação do sistema em uma práxis de libertação que as retire da situação de sujeição em que se encontram.

É importante ressaltar as conseqüências políticas práticas da visão de Dussel a respeito da intersubjetividade comunitária de vítimas. Se os movimentos sociais são "um tipo fluido ou fragmentário de sujeitos sóciohistóricos, que aparecem e desaparecem em conjunturas bem determinadas" (DUSSEL, 2002:533), isso significa que não existe um sujeito privilegiado da práxis de libertação (o partido, a classe, o proletariado), mas um ou vários sujeitos sócio-históricos, trabalhando em uma ou várias frentes de libertação, conforme as necessidades políticas imediatas, em uma ação harmônica, mas não uníssona.

Os sujeitos sócio-históricos não seguem à toa; deve-se destituir o proletariado (ou o partido, ou o intelectual, ou o líder político, ou qualquer outro sujeito privilegiado da ação transformadora) do comando da nau para que a multiplicidade das comunidades intersubjetivas assuma o leme e determine, em conjunto, a direção em que deseja seguir. É muito útil, nesse sentido, a idéia de tradução de Boaventura de Sousa Santos, para quem a política emancipatória exige o desenvolvimento de uma tópica de emancipação nas diferentes comunidades interpretativas (que Dussel denomina "frentes 
de libertação") e nas redes existentes entre elas. Estabelecida essa tópica de emancipação, o autor afirma que:

Haverá senso comum emancipatório quando os topoi emancipatórios desenvolvidos numa dada comunidade interpretativa encontrarem tradução adequada nos topoi de outras comunidades e se converterem, assim, em topoi gerais. [...] Só pode haver emancipação através de significações partilhadas, através da invenção convincente de novos topoi emancipatórios. A única vanguarda legítima é o senso comum de vanguarda (SANTOS, 2000:110 - grifos no original).

Assim, os movimentos sociais devem ser respeitados em sua pluralidade, sem a necessidade de liderança ou prevalência de um determinado sujeito sobre os restantes, sendo possível a convivência de uma multiplicidade de sujeitos sócio-históricos da práxis de libertação agindo em conjunto em prol da transformação do sistema que gera vítimas. Levando essa forma de pensamento às últimas consequiências, Foucault e Deleuze (na mesma entrevista citada acima) afirmam que:

G.D.: Se se considera a situação atual, o poder possui forçosamente uma visão total ou global. [...] Frente a essa política global de poder se fazem revides locais, contra-ataques, defesas ativas e às vezes preventivas. Nós não temos que totalizar o que apenas se totaliza do lado do poder e que só podemos totalizar restaurando formas representativas de centralismo e de hierarquia. Em contrapartida, o que temos que fazer é instaurar ligações laterais, todo um sistema de redes, de bases populares. [...] O movimento atual tem muitos focos, o que não significa fraqueza e insuficiência, pois a totalização pertence sobretudo ao poder e à reação. [...] Mas como conceber as redes, as ligações transversais entre esses pontos ativos descontínuos entre países ou no interior de um mesmo país?
M.F.: [...] Se é contra o poder que se luta então todos aqueles sobre os quais o poder se exerce como abuso [...] podem começar a luta onde se encontram e a partir de sua atividade (ou passividade) própria. E iniciando essa luta $[. .$.$] entram no processo revolucionário.$ Evidentemente como aliado do proletariado, pois, se o poder se exerce como ele se exerce, é para manter a exploração capitalista. Eles servem realmente à causa da revolução proletária lutando precisamente onde a opressão se exerce sobre eles. [...] Isto quer dizer que a generalidade da luta não se faz [...] por meio da totalização teórica [...]. O que dá generalidade à luta é o próprio sistema de poder, todas as suas formas de exercício e aplicação (FOUCAULT, 2004a:74-78).

Deve-se, portanto, reconhecer a pluralidade de comunidades de vítimas, que unidas em movimentos sociais criam intersubjetivamente novos consensos contra-hegemônicos que têm por objetivo a transformação do sistema gerador de vítimas. Nessa pluralidade não existe um local privilegiado de combate; não há capitão, é o próprio vento que indica a direção do barco. Agindo em harmonia, mas em frentes de libertação distintas, os vários sujeitos sócio-históricos contribuem igualmente para a práxis de libertação. O que dá generalidade à luta é o próprio sistema de poder, de modo que a única vanguarda legítima é o senso comum de vanguarda.

\section{CONCLUSÃO}

Analisamos o papel ocupado pelo sujeito na Ética da Libertação de Enrique Dussel. Sendo a capacidade de ação dos seres humanos sempre limitada, toda ação humana é potencialmente geradora de vítimas, uma vez que é impossível prever todas as suas consequiências. Assim, é necessário efetuar 
uma permanente crítica dessas ações, ponto de partida necessário para a transformação da realidade que gera vítimas não-intencionais. É nesse momento que aparece o sujeito da práxis de libertação, como agente criador de novas frentes de libertação, capazes de transformar a realidade a partir de conteúdos que permitam o desenvolvimento libertador da vida negada.

Esse sujeito é, em primeiro lugar, um sujeito corporal vivo. Negação do sujeito transcendental-formal da Modernidade, o sujeito da ação política transmoderna toma sempre como pressuposto a vida humana concreta. Assim, deve-se ter em conta os sujeitos vivos não como entidades racionais ou como vontades autônomas, mas como seres corporais vivos, simultaneamente biológicos e culturais, capazes de sentir fome e dor no coração - mas que, apesar disso, não choram à toa, e lutam pela eliminação de seus sofrimentos e pela sua libertação do sistema que produz vítimas.

Além disso, é a própria vítima que atua como sujeito da práxis de libertação. Desprezando líderes e vanguardas, a vítima toma consciência de sua situação de opressão e resolve, por si mesma, atuar como agente de sua libertação, deixando de ser objeto para se afirmar como sujeito de sua própria história. Contudo, ao interpelar os que não são vítimas os torna responsáveis por sua opressão e os co-responsabiliza por sua libertação, tornando-os também sujeitos da práxis de libertação. A vítima não sorri à toa, devora os catequizadores e recusa os autonomeados representantes de si mesma, agindo como sujeito ativo na transformação de sua realidade. Escolhe seus próprios aliados, interpelando-os e os tornando co-responsavelmente articulados a ela, mas jamais seus representantes ou formuladores teóricos de seu pensamento.

Finalmente, a vítima não age solipsisticamente, mas pela formação de intersubjetividades comunitárias a partir de uma comunidade de vida, por meio da qual se forma um consenso anti-hegemônico em prol da transformação da realidade que nega suas vidas concretas. A pluralidade de movimentos sociais não segue à toa, rejeita a prevalência de um grupo social como capitão na luta pela libertação, nega a possibilidade de uma única perspectiva e conduz o barco, mediante de um consenso intersubjetivo, rumo à libertação.

\section{REFERÊNCIAS}

BOBBIO, Norberto (1995). Direito e Estado no Pensamento de Emanuel Kant. Brasília: UnB.

DESCARTES, René (1961). Discurso do Método. Rio de Janeiro: EdiOuro.

DUSSEL, Enrique (2002). Ética da Libertação na idade da globalização e da exclusão.

Petrópolis: Vozes

FONSECA, Ricardo Marcelo (2002).

Modernidade e Contrato de Trabalho: do Sujeito de Direito à Sujeição Jurídica. São Paulo: LTr.

FOUCAULT, Michel (2000). Em Defesa da Sociedade. São Paulo: Martins Fontes.

FOUCAULT, Michel (2001a). A Ordem do Discurso. São Paulo: Loyola.

FOUCAULT, Michel (2001b). A Verdade e as Formas Jurídicas. Rio de Janeiro: Nau.

FOUCAULT, Michel (2001c). L'Herméneutique du Sujet. Paris: Gallimard/Seuil.

FOUCAULT, Michel (2003). Ditos e Escritos IV: estratégias, saber-poder. Rio de Janeiro:

Forense Universitária. 
FREIRE, Paulo (1974). Pedagogia do Oprimido. Rio de Janeiro: Paz e Terra.

GABEIRA, Fernando (1979). O que é isso companheiro? Rio de Janeiro: Codecri.

GUANDALINI JR., Walter; MONTOYA, Daniel K (2003). O Sujeito de Direito e o Novo Código Civil - desonra ou Harpias?, disponível em 2 de outubro na página da web $<$ http://www.historiadodireito.com.br/textos/ sujeito\%20de\%20direito.htm>.

GUANDALINI JR., Walter (2004). Da Ascese à Disciplina: a ética protestante e a constituição do sujeito capitalista. In: Revista da Faculdade de Direito da Universidade Federal do Paraná, n. ${ }^{\circ}$ 41. Curitiba: SER/UFPR, p. 115-129.

KANT, Immanuel (1999). Crítica da Razão Pura. São Paulo: Nova Cultural.

LUDWIG, Celso Luiz (2004a). Da ética à filosofia política crítica na transmodernidade: reflexões desde a filosofia de Enrique Dussel. Repensando a Teoria do Estado (Org.: Ricardo Marcelo Fonseca). Belo Horizonte: Fórum.
LUDWIG, Celso Luiz (2004b). A transformação jurídica na ótica da filosofia transmoderna: a legitimidade dos novos direitos. In: Revista da Faculdade de Direito da Universidade Federal do Paraná, n. ${ }^{\circ}$ 41. Curitiba: SER/UFPR, p. 29-42.

LUDWIG, Celso Luiz (2006). A transformação da filosofia e a libertação. In: Revista da Faculdade de Direito da Universidade Federal do Paraná, no 44. Curitiba: SER/UFPR, p. 43-59. ROUANET, Sérgio Paulo (1992). As Razões do Iluminismo. São Paulo: Companhia da Letras.

ROUANET, Sérgio Paulo (1993). Mal estar na Modernidade. São Paulo: Companhia das Letras.

SANTOS, Boaventura de Sousa (2000). A Crítica da Razão Indolente: contra o desperdício da experiência (vol. 1 - Para um novo senso comum: a ciência, o direito e a política na transição paradigmática). São Paulo: Cortez. 